\title{
STUDIES ON THE EFFECT OF THE ACTION OF DIGITALIS ON THE OUTPUT OF BLOOD FROM THE HEART.
}

\author{
II. The Effect on the Output of the Hearts of Dogs Subject \\ to Artificial Auricular Fibrillation \\ BY HAROLD J. STEWART AND ALFRED E. COHN \\ (From the IIospital of the Rockefeller Institute for Medical Research, New York)
}

(Received for publication June 16, 1932)

That an effect of giving digitalis to normal unanesthetised dogs is to decrease cardiac output and size, and to increase the extent of ventricular contractions has previously been reported (1). To study in dogs, phenomena comparable with heart failure with edema in human beings, experiments were undertaken employing several methods. The one finally adopted was to bring about, artificially, insufficiencies of the mitral valve (2). Aftet a lesion had been made by operation, the hearts increased in size. The dogs exhibited no signs of heart failure, however, and were able to run on a treadmill as normal dogs do. When digitalis was given to them, the results were similar to those occurring in normal dogs. These were decrease in cardiac output and cardiac size, and increase in the extent of ventricular excursions (2). A situation was, however, still wanting, in which to test the effect of giving digitalis to animals the hearts of which were in a poor state functionally, a situation, in short, in which the output of blood per minute from the heart was diminished and the heart dilated. Stewart and Gilchrist (3) and Stewart and Crawford (4) have shown that such a situation could be managed. They found that when the hearts of normal dogs were made subject to auricular fibrillation, artificially induced, the volume output of blood per minute from the heart diminishes (3), and dilatation of the heart, detected by increase in size of its shadow in x-ray photographs, may occur (4). These changes, decrease in output and increase in size of the heart, were already present one hour after the onset of auricular fibrillation. Here then was a preparation suitable for testing in dogs the effect of giving digitalis when the functional capacity was diminished. In this report there are described, accordingly, observations on the effect of giving digitalis on the cardiac output per minute, cardiac size, ventricular and femoral pulse rates per minute in unanesthetized trained dogs during auricular fibrillation. 


\section{METHODS}

All the dogs were trained to breathe in a Benedict-Roth spirometer for 20 to 30 minutes a day for ten days to two weeks before they were used. At the end of this time they lay quietly on the table without emotional disturbance, while measurements of oxygen consumption were made and other procedures were carried out. It was possible to decide at the first or second trial whether a given dog was a satisfactory subject. In the technique of measuring oxygen consumption, the rubber mask described by Blalock was used (5).

The operative procedure has already been described (6). Briefly, wire electrodes were sutured to the right auricle (Figure 1). The opera-

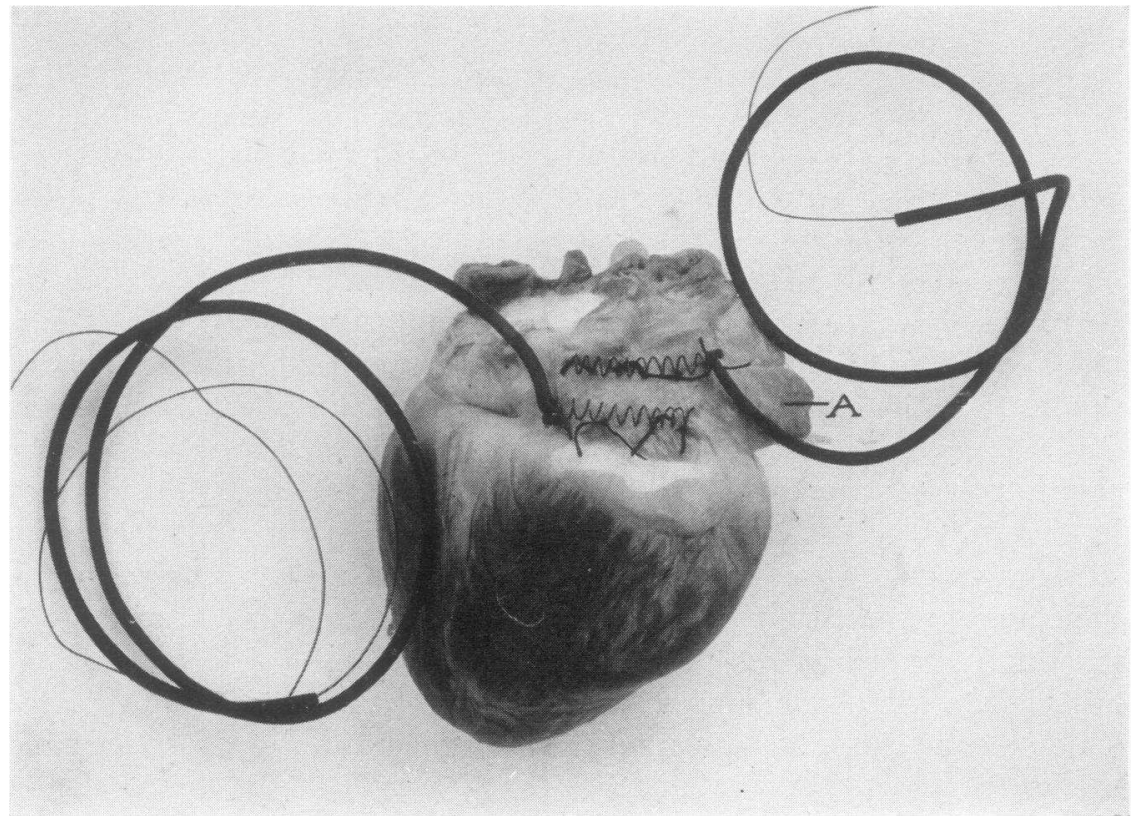

Fig. 1. This Figure Shows the Manner in Which the Spiral Wire Electrodes Were Sutured to the Right Auricle $A$ is the right auricular appendix.

tions were performed with sterile precautions, the dogs being anesthetized with ether given by the intratracheal method. After recovery from the preliminary operation, the auricles of the heart were made to fibrillate by stimulating them through these electrodes with faradic current obtained from one to three dry cell batteries placed in the primary circuit of a DuBois-Reymond induction coil. In order to be certain that the auricles were fibrillating, as well as to calculate the number of effective beats, a tracing of the femoral pulse was recorded simultaneously on the same film with an electrocardiogram (Figure 2)(7). The femoral pulse was 
transmitted by rubber tubing from a rubber cuff applied to the right hindleg through an Erlanger capsule modified by Kolls (8), and Kubie (9), to a Frank capsule placed in front of the camera. The rubber cuff on the leg was inflated with air to a pressure near the diastolic level. The movements of a beam of light focused on a mirror glued to the membrane of the Frank capsule were reflected to the lens of the camera and were traced on the moving sensitive film simultaneously with the electrocardiogram. Nonpolarizable electrodes were placed on the right fore-leg and the left hind-leg for the derivation of Lead II of the electrocardiogram.

Samples of arterial blood were drawn from a femoral artery and those of mixed venous blood from the right ventricle by a special cannula inserted into that chamber through the right external jugular vein (10). The oxygen contents of these samples were estimated by the Van Slyke and Neill manometric method (11) for calculation of the arteriovenous oxygen differences. Immediately after the blood samples were drawn, the oxygen consumption was measured with a Benedict-Roth spirometer equipped with a graphic recording drum. Data were available, therefore, for calculating the minute volume output of the heart according to the Fick principle (12).

$\mathrm{X}$-ray photographs of the heart taken at a distance of 2 meters were made according to the method described by Stewart for obtaining photographs of the hearts of dogs under uniform conditions. The x-ray shadows of the heart were traced on thin paper and the areas measured with a planimeter (13).

\section{Plan of observations}

The day after the preliminary operation the following observations were made. The dogs, in a basal metabolic state, lay quietly on the table without anesthesia. A set of observations consisting of : an x-ray photograph of the heart, samples of arterial and of mixed venous blood, measurement of oxygen consumption, and electrocardiograms together with simultaneous femoral pulse tracings, was taken during the period of normal cardiac rhythm, hereafter called the "period of normal rhythm." Taking a complete set of observations required usually 30 to 45 minutes. The right auricle was then made subject to fibrillation. At the end of approximately one hour, designated the "period of auricular fibrillation," while the auricles were still fibrillating, a second set of observations was made. Then, while this rhythm was maintained by continuing faradic stimulation, tincture of digitalis (Upsher Smith) was injected intravenously in an amount calculated to be 25 to 30 per cent of the lethal dose. ${ }^{1}$

1 This amount was chosen because Robinson and Wilson (14) found the therapeutic dose of digitalis for cats to be 30 per cent of the calculated lethal dose, and because Cohn (15) found that the dose for cats must be multiplied by the factor 1.16 to arrive at a comparable quantity for dogs. We have accordingly injected this amount of the tincture. To several dogs we administered digifoline (Ciba) $0.5 \mathrm{cc}$. per kilogram of body weight $(16,17)$. The same phenomena resulted irrespective of the preparation that was given. 

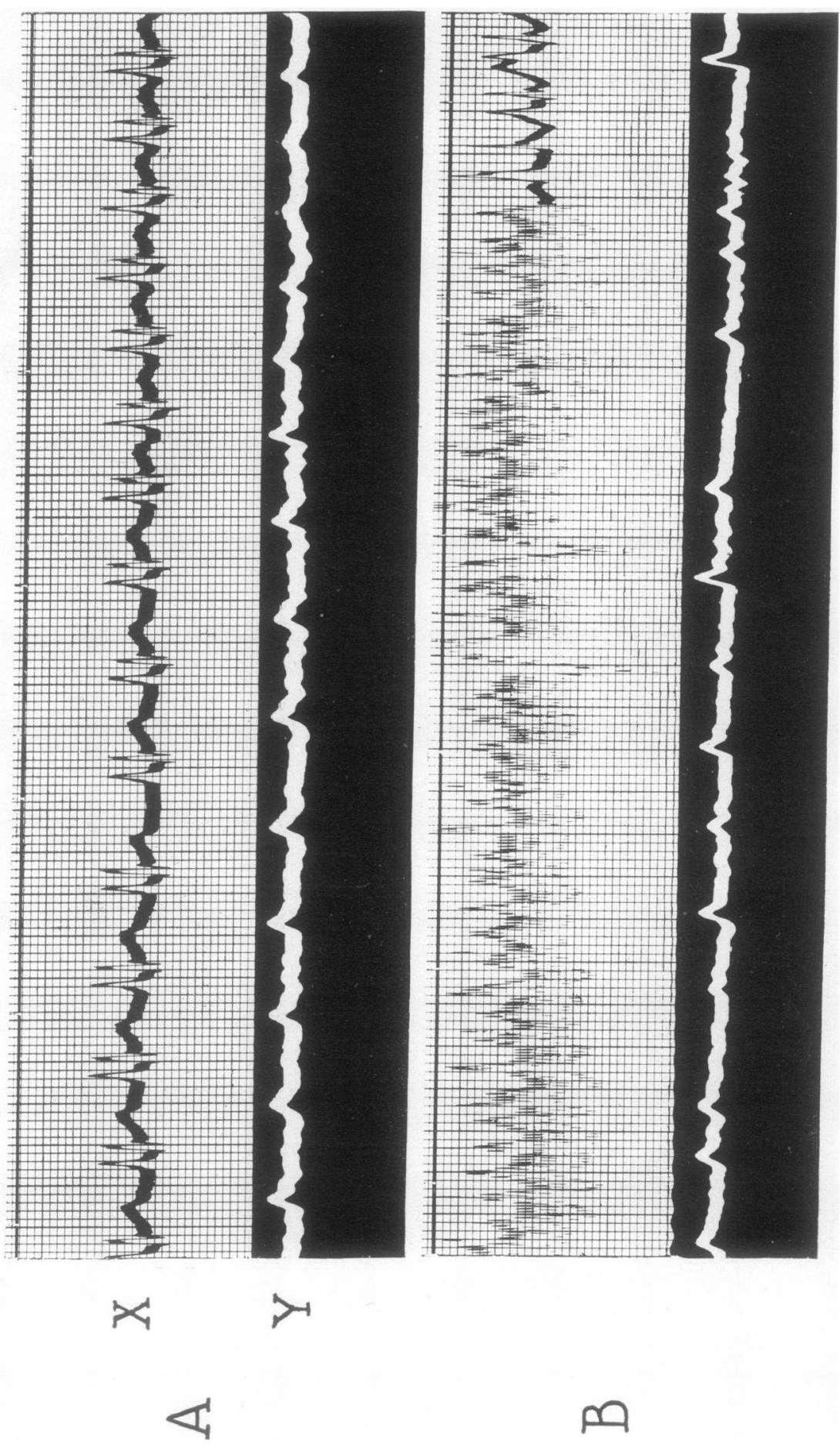

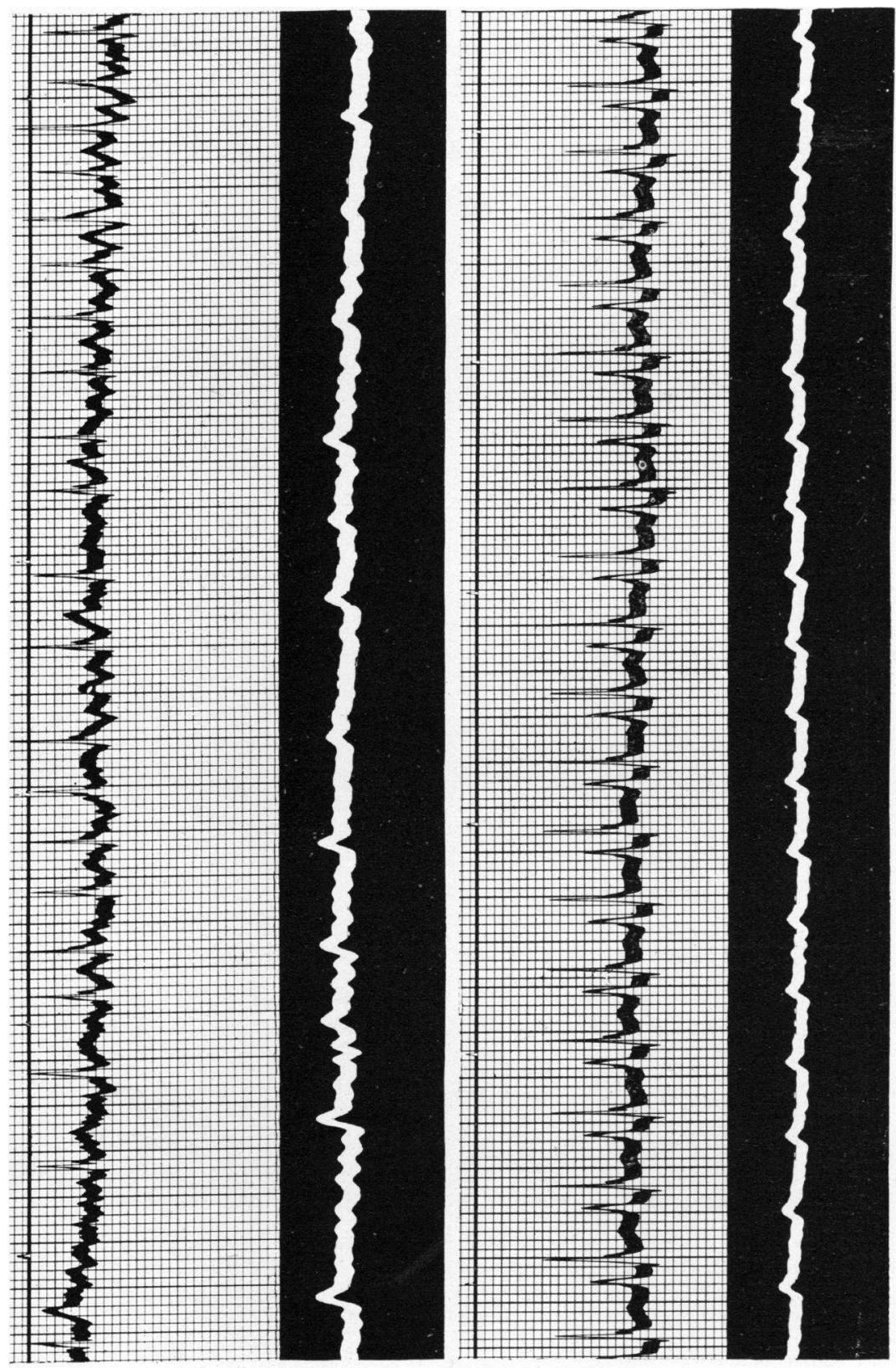

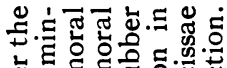

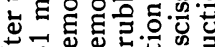

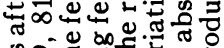
8

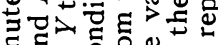

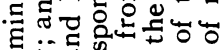

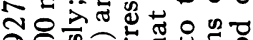

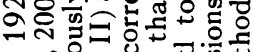
ن -

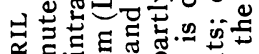

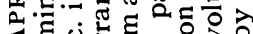
यद्

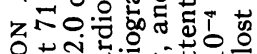

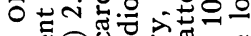

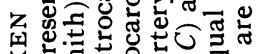
पे है

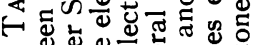
. के 존.2

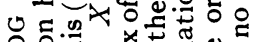

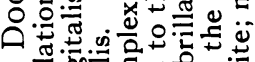

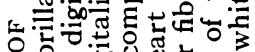

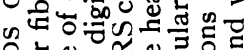

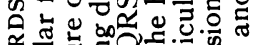
골 G.

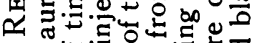
되 के

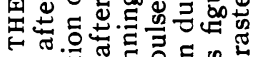

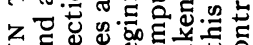
的瓶政

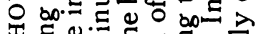

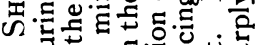

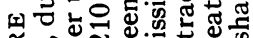
m-

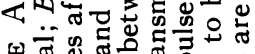
(1)

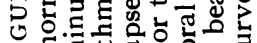

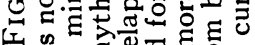

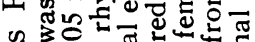
छ

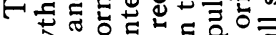

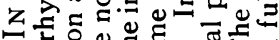

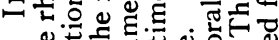

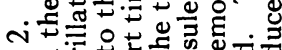

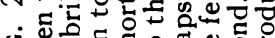
ن

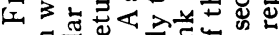
过宩记

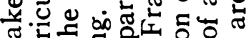

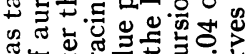
उั0

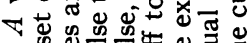

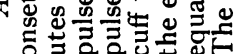




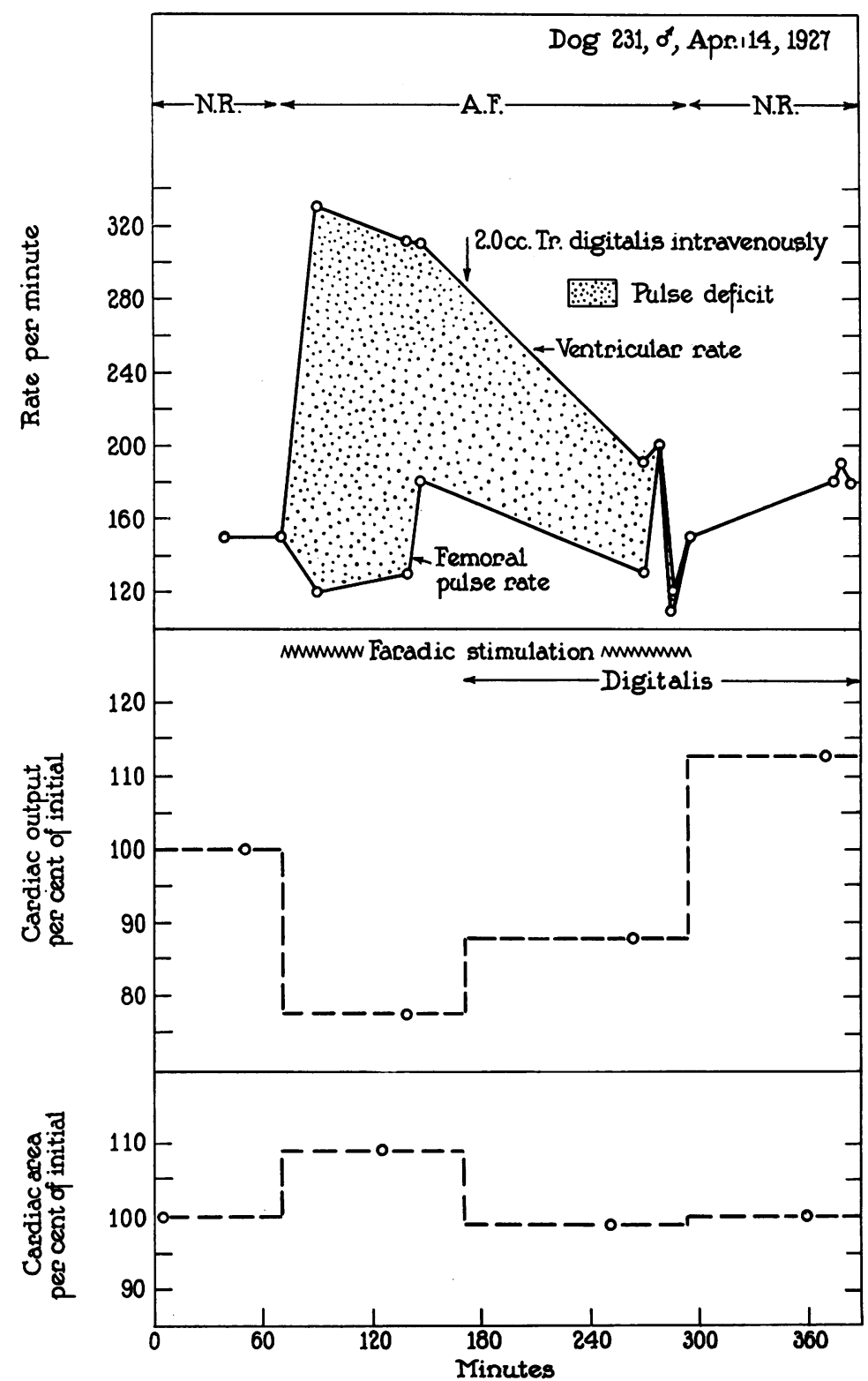

Fig. 3. In This Figure Is Shown the Effect of Giving Digitalis on Cardiac Output, Cardiac Size, Ventricular Rate and Femoral Pulse Rate per Minute in Dog 231 (April 14, 1927) During Artificial Auricular Fibrillation.

In this figure as well as in Figure 4, the points on the curves show the exact time (abscissa) at which each observation was made. In order to bring into relief the relations between the various situations at these times, the curves are drawn in dotted straight lines as though these relations existed throughout the various periods. In this figure and in Figure 4, N.R. indicates normal rhythm and A.F., auricular fibrillation. 


\begin{tabular}{|c|c|c|c|c|c|c|}
\hline \multirow{2}{*}{ 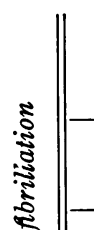 } & 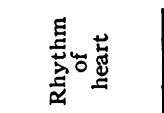 & 总 & 这 & 径 & 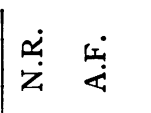 & نَ \\
\hline & 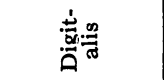 & $\stackrel{s}{3}$ & 萨 & & \multicolumn{2}{|c|}{. } \\
\hline & 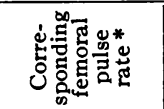 & 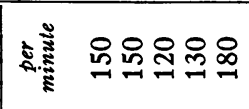 & \multicolumn{2}{|c|}{ 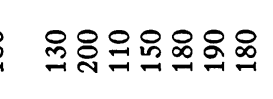 } & 용욤요 & 옥오요 \\
\hline & 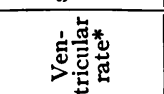 & 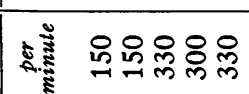 & \multicolumn{2}{|c|}{ 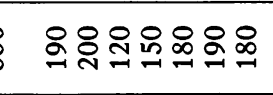 } & \&:욤유 & 요묙 \\
\hline & 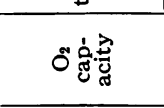 & 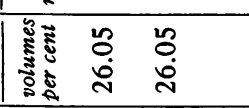 & 学 & 商 & 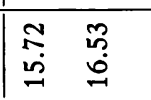 & 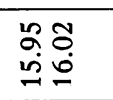 \\
\hline & 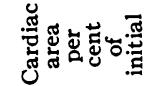 & 15: 8 & a & 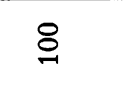 & $\stackrel{8}{1}$ & \&むt \\
\hline & 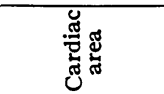 & 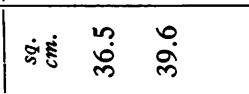 & $\dot{0}$ & 柋 & 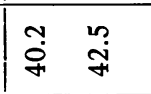 & 瓷号 \\
\hline & 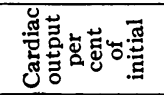 & 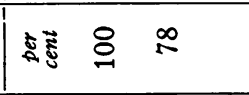 & $\infty$ & $\stackrel{\Xi}{=}$ & $\nexists \approx$ & $\infty$ \\
\hline & 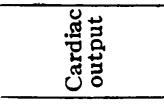 & 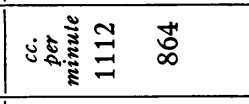 & $\stackrel{0}{2}$ & $\overrightarrow{\mathrm{d}}$ & 粗 & 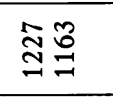 \\
\hline & 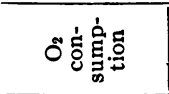 & ن் & $\vec{a}$ & $\infty$ & $\stackrel{2}{7}$ & 足苛 \\
\hline & 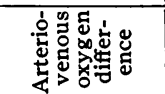 & 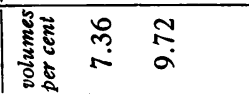 & $\widetilde{\widetilde{a}}$ & 萬 & $\mid \begin{array}{ll}0 \\
0 \\
0\end{array}$ & 产苔 \\
\hline & 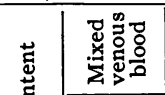 & 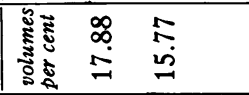 & 总 & 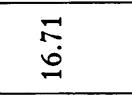 & 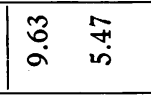 & 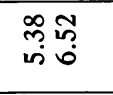 \\
\hline & 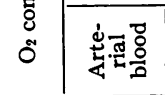 & 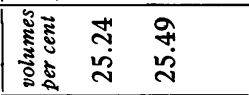 & 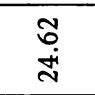 & 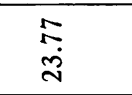 & 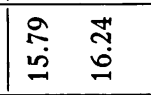 & 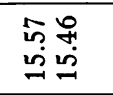 \\
\hline & 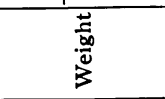 & 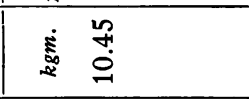 & & & $\frac{m}{9}$ & \\
\hline & 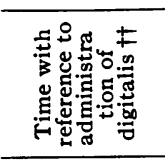 & 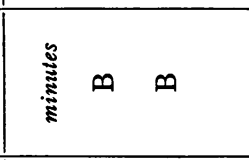 & 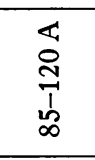 & 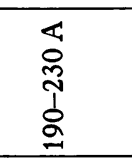 & $\infty \infty$ & 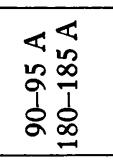 \\
\hline & 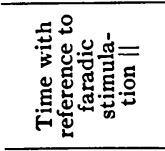 & 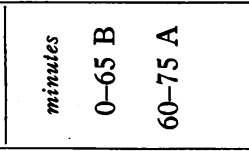 & 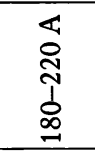 & 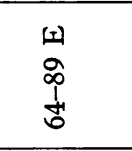 & $\begin{array}{|ll|} & 4 \\
0 & 0 \\
0 & 0 \\
0 & 1 \\
0 & 0 \\
\end{array}$ & 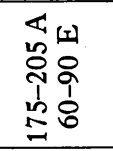 \\
\hline & 㟧 & 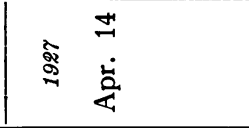 & & & \begin{tabular}{|l|}
$\overrightarrow{\vec{a}}$ \\
$\overrightarrow{\mathrm{a}}$
\end{tabular} & \\
\hline & 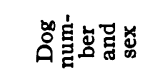 & $\overrightarrow{\sigma^{2}}{ }_{0}$ & & & & \\
\hline
\end{tabular}




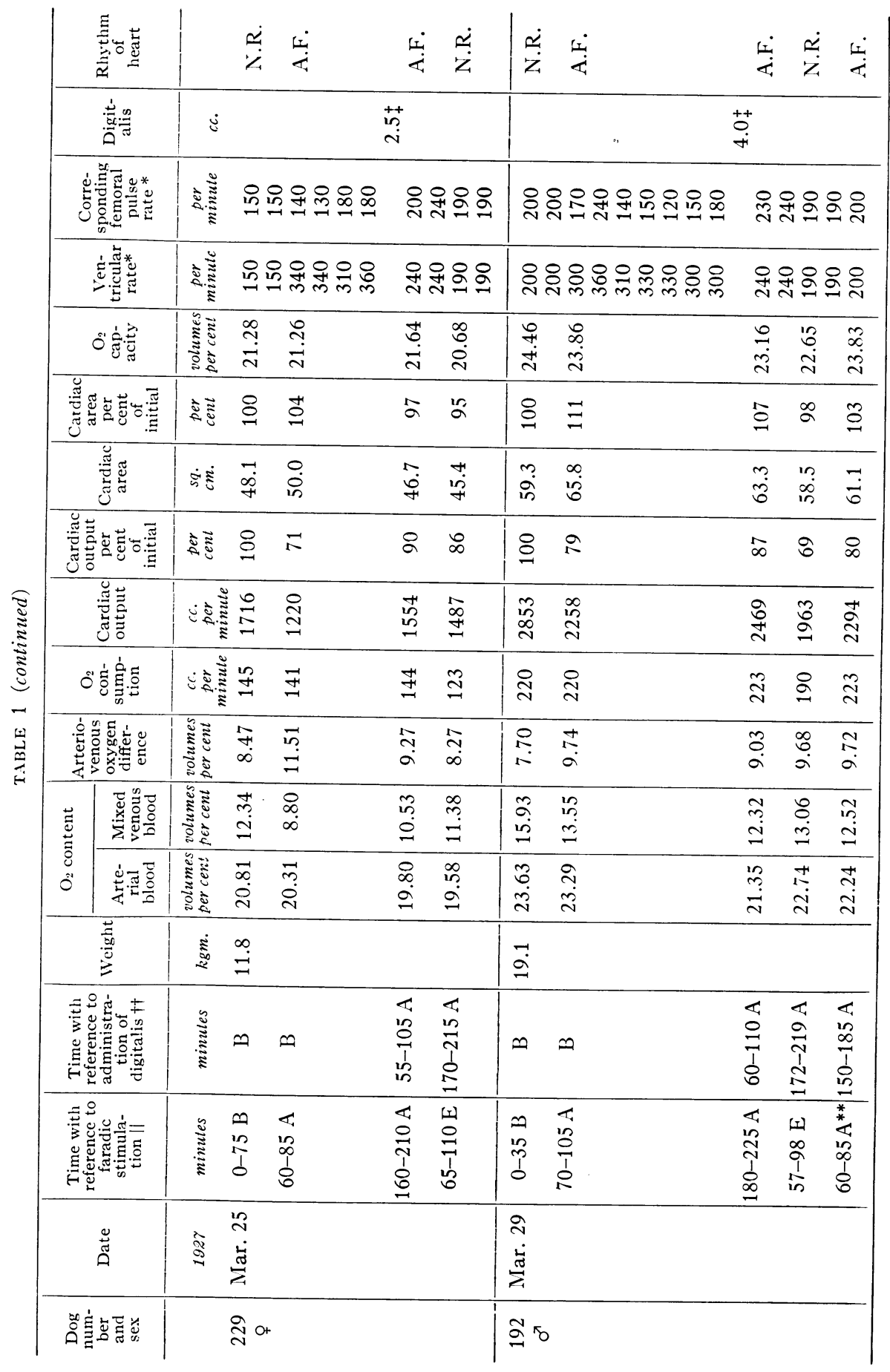


HAROLD J. STEWART AND ALFRED E. COHN

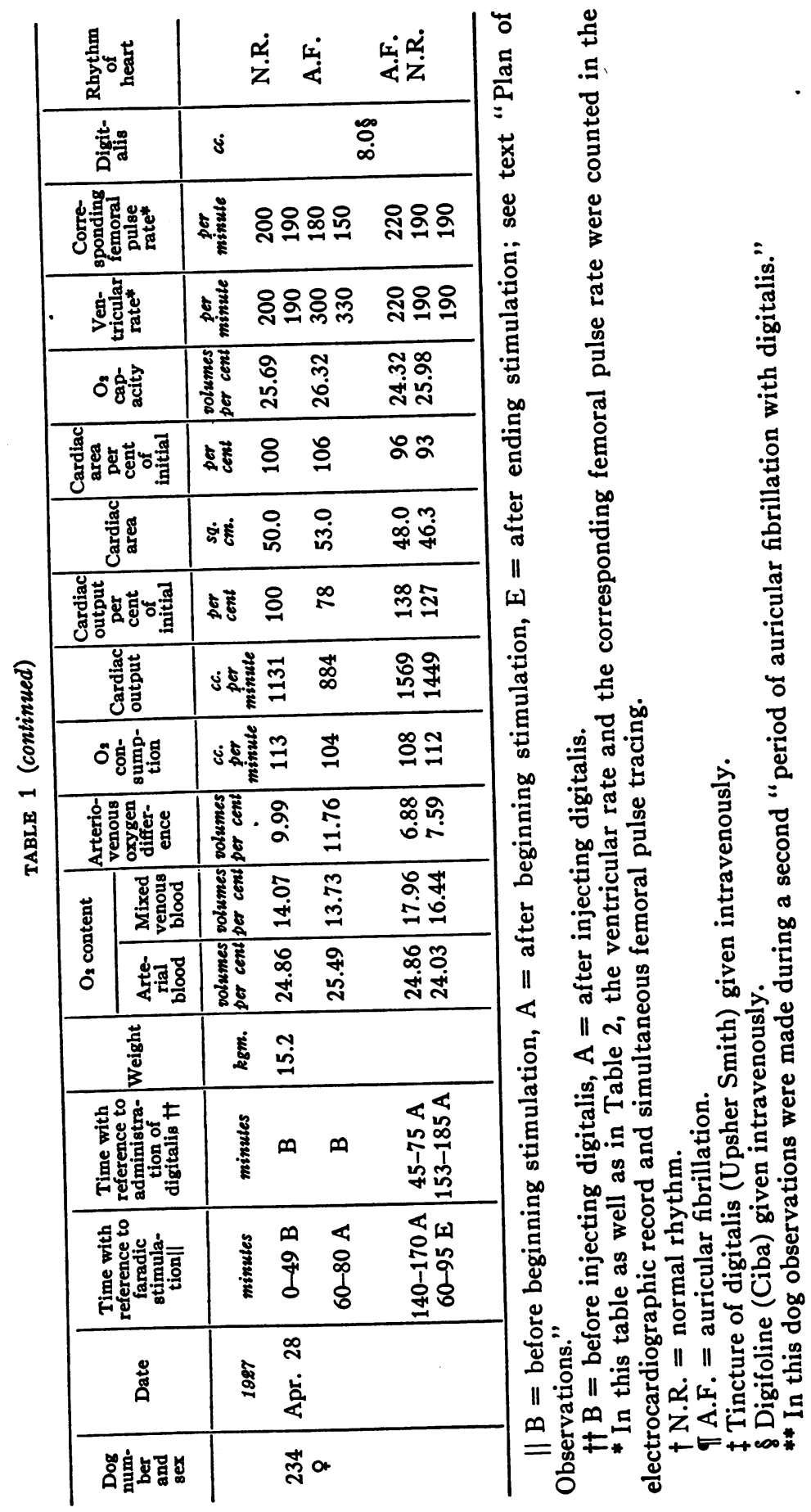


Approximately one hour later, during the "period of auricular fibrillation with digitalis," the auricles still fibrillating, a third set of observations was made. Stimulation of the auricles was then discontinued and the rhythm of the heart became normal again. After another hour, designated the "period of normal rhythm with digitalis," a fourth set of observations was made. Deviation from this schedule, whenever it occurred, is shown in the tables.

There are complete observations in four dogs. The results secured in the case of dog 231 serve to illustrate the course of events (Table 1, Figure 3 ). When the heart was beating normally at a rate of 150 per minute its output was $1112 \mathrm{cc}$. per minute, and the area of the heart measured 36.5 sq. cm. (Table 1, April 14, 1927). One hour after the onset of auricular fibrillation and while this rhythm was still present, the ventricular rate being 300 to 330 (Figure 2) and the femoral pulse rate 120 to 180 per minute, the cardiac output fell to $864 \mathrm{cc}$. per minute or 78 per cent of its initial value (Table 1, Figure 3), and the area of the heart measured 39.6 sq. cm., an increase to 109 per cent of its initial size. While the auricles were fibrillating, tincture of digitalis (Upsher Smith) 2.0 grams was given intravenously. Eighty-five minutes later, under the influence of digitalis, the ventricular rate decreased further from 200 to 120 , and the corresponding femoral pulse rate from 200 to 110 per minute, the pulse deficit being smaller; the heart was, in short, still beating irregularly but more slowly and more forcibly, there being only a few ineffective beats. The cardiac output increased to 976 cc. per minute ( 88 per cent of its initial value) and its size decreased to $36.0 \mathrm{sq}$. $\mathrm{cm}$. (99 per cent of its initial size). Then stimulation of the auricles was discontinued and the rhythm of the heart again became normal. One hour later the cardiac rate was 190 to 200 per minute, the heart still being under the influence of digitalis. Since there was no longer a pulse deficit, the cardiac output increased to $1261 \mathrm{cc}$. per minute (113 per cent of the initial) though the area of the heart remained unchanged ( $36.5 \mathrm{sq} . \mathrm{cm}$., 100 per cent). When the observations were repeated one week later (April 21, 1927) similar results were obtained (Table 1), with this exception that cardiac output and cardiac size both diminished when the rhythm of the heart became regular again in the final (fourth) period.

Summary: With the onset of auricular fibrillation the cardiac output decreased and the heart dilated. When digitalis was given the size diminished and the output increased; that is to say, the capacity of the heart to expel blood increased. The results in the three other dogs were similar to these. The most frequent effect observed after the end of stimulation, when the rhythm again became regular, was further decrease in the size of the heart and a decrease in output. In other instances, as in the one described in detail, cardiac size remained unchanged from that in the fibrillatory state and the cardiac output increased. 
HAROLD J. STEWART AND ALFRED E. COHN

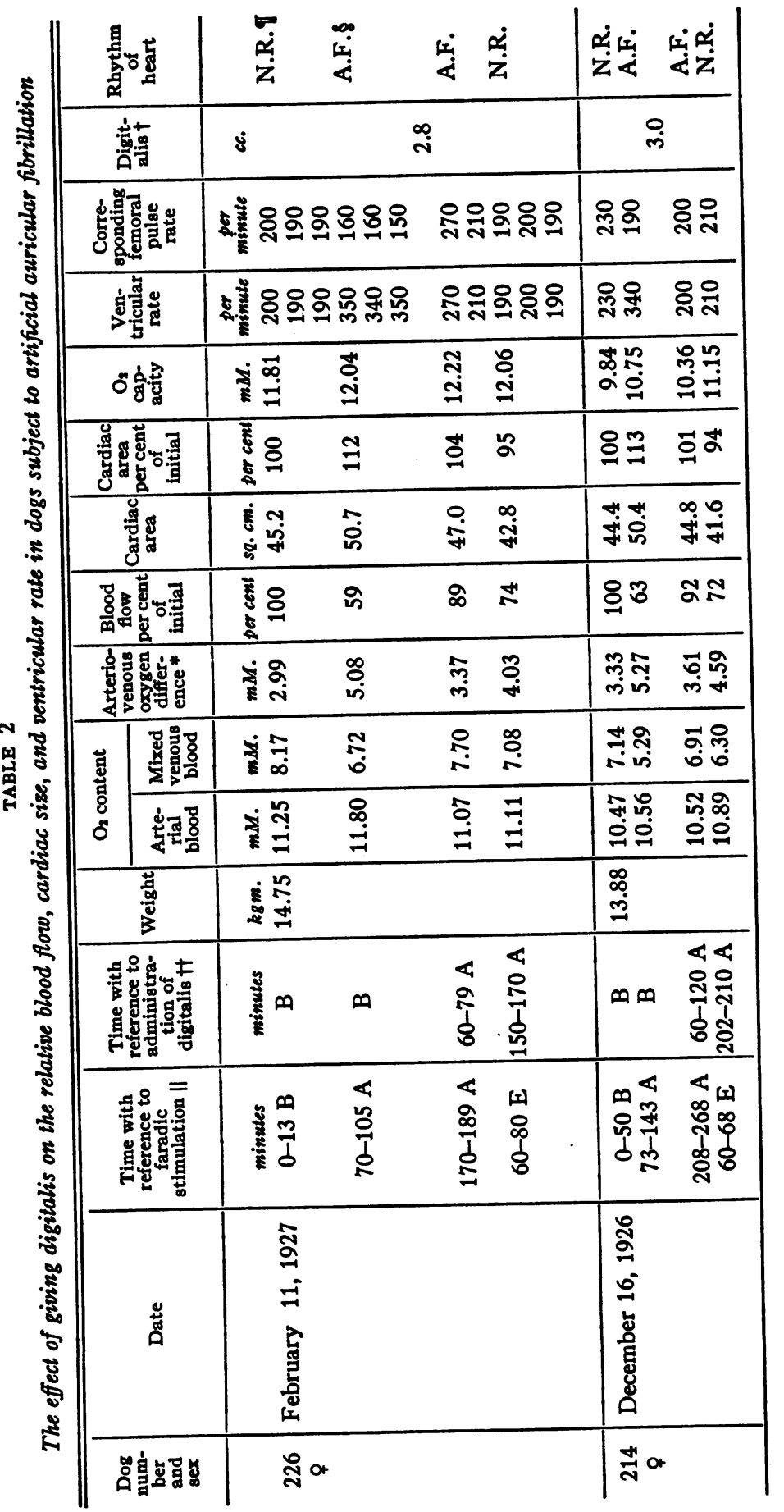




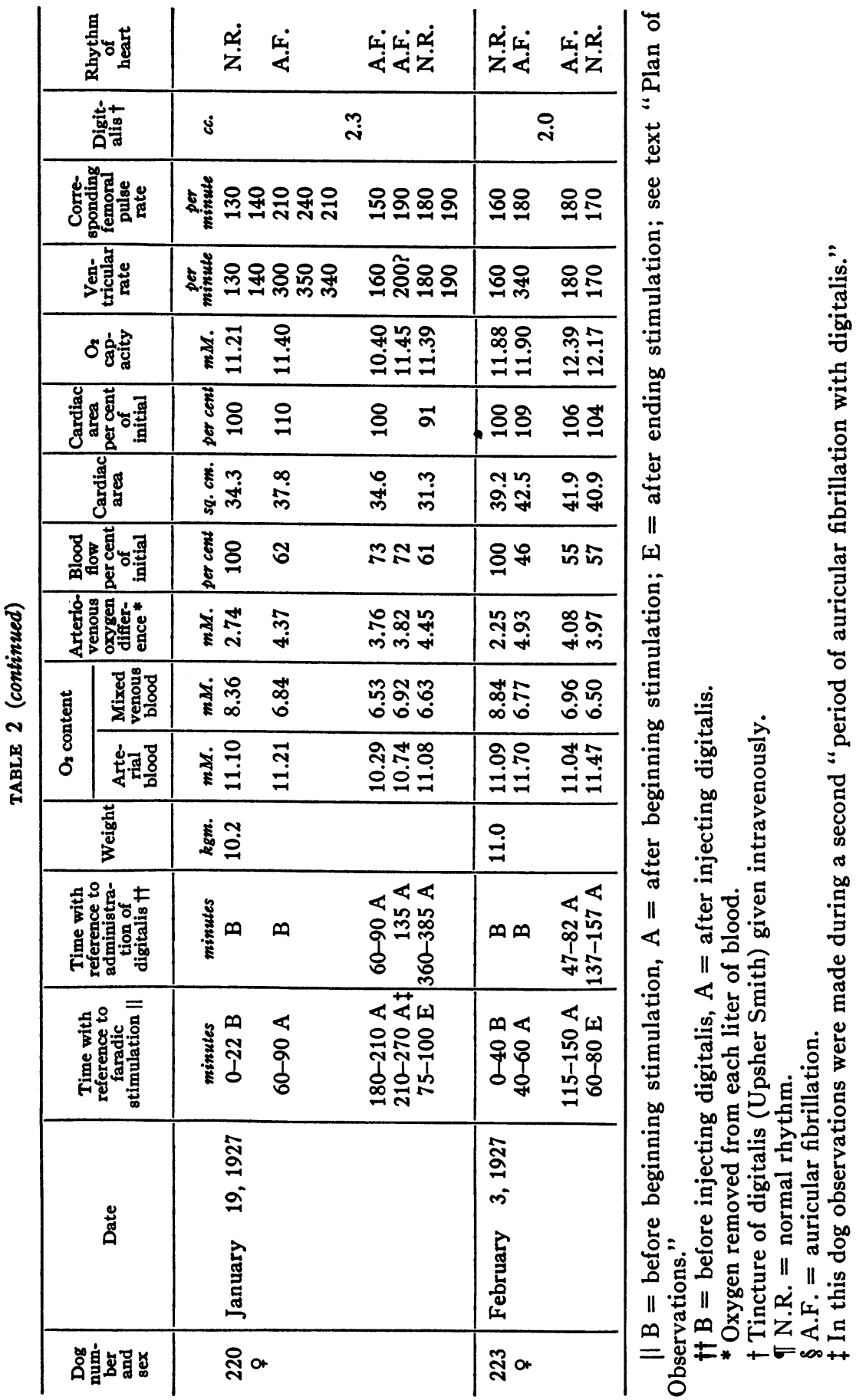




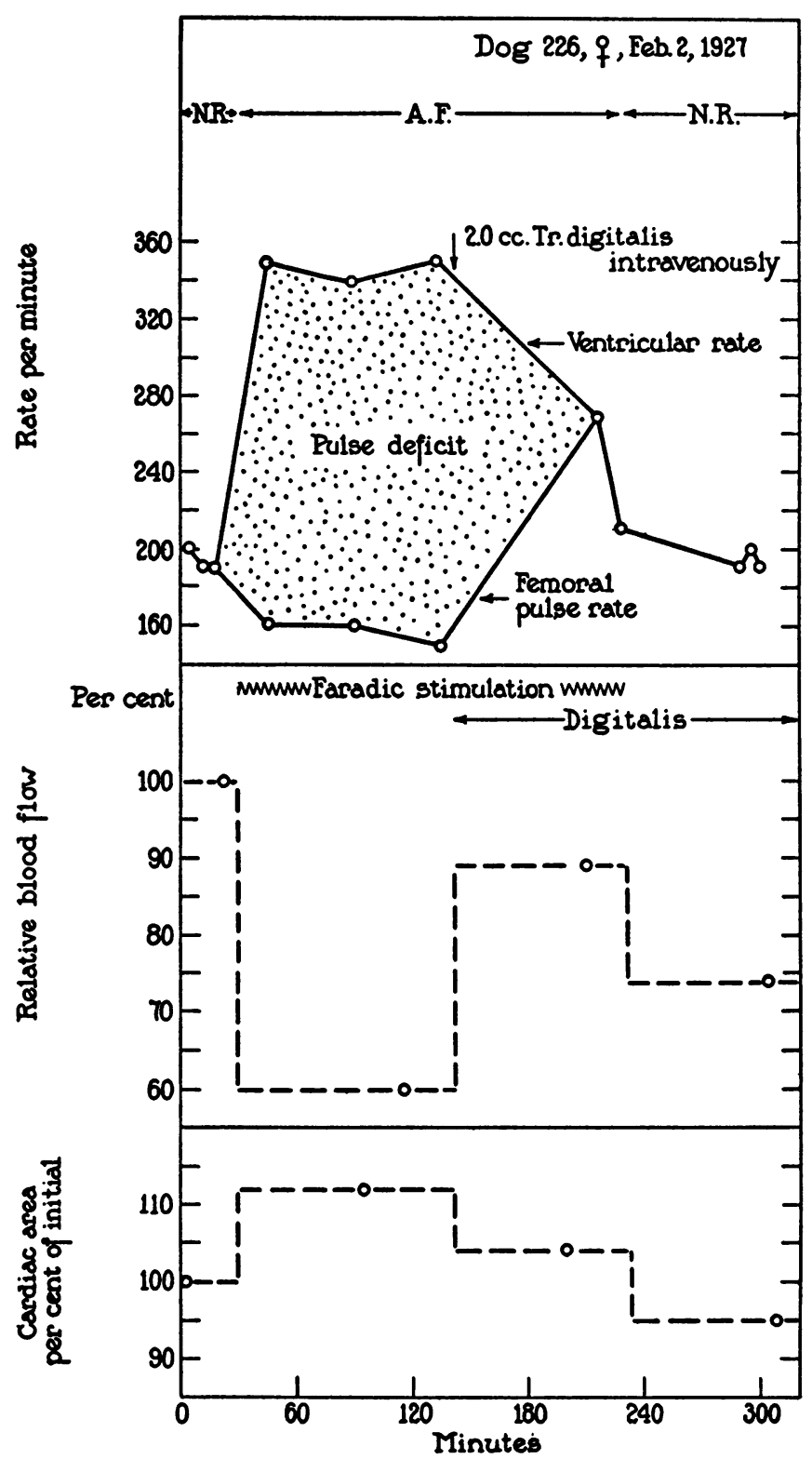

Fig. 4. In This Figure Is Shown the Effect of Giving Digitalis on the Relative Blood Flow, Cardiac Size, Ventricular and Femoral Pulse Rates per Minute in Dog 226 During Artificial Auricular Fibrillation. 
In four untrained dogs similar observations were made (Table 2). The arteriovenous oxygen difference was measured representing, as it does, the oxygen consumed by the tissues per liter of blood, and from this the relative blood flow ${ }^{2}(6)$ has been calculated, the control period being placed at 100; the results in all these measurements are similar to those in which the cardiac output was measured. Dog 226 (Table 2, Figure 4) may serve to illustrate the course of events. There was decrease in relative blood flow and increase in cardiac size when the cardiac mechanism was that of auricular fibrillation; increase in output and decrease in size when digitalis was given during this rhythm and finally, decrease in output and decrease in cardiac size with the return of the normal rhythm. The results in the three other dogs are similar.

\section{$A$ note on the effect of giving digitalis to a dog in the presence of edema artificially induced}

In dog 265, edema of the extremities occurred as a result of taking sodium bromide ${ }^{3}(18,19,20,21)$. The fluid intake was uniform, being $1500 \mathrm{cc}$. a day. The diet consisted of milk and eggs given by stomach tube at the same time each evening. The output of urine was measured. The dog was trained in the use of the spirometer for measuring oxygen consumption. All measurements were made when the dog was in a basal metabolic state. On November 27, 1928, when edema appeared, the cardiac output measured $1550 \mathrm{cc}$. per minute and the area of the heart 48.3 sq. $\mathrm{cm}$.; the left and right ventricular excursions measured in moving x-ray films (1) $2.8 \mathrm{~mm}$. and $3.4 \mathrm{~mm}$. respectively (Table 3, Figure 5). Tincture of digitalis (Upsher Smith) $2.7 \mathrm{cc}$. was given intravenously to this dog after these measurements had been made. The output of urine increased, the dog lost weight, and became free of edema on November 30. Twenty-four hours after the administration of digitalis, cardiac output increased to $2100 \mathrm{cc}$. (136 per cent of the initial output), cardiac size decreased to $47.5 \mathrm{sq} . \mathrm{cm}$. ( 89 per cent) and the left and right ventricular excursions both increased $(4.8 \mathrm{~mm}$. and $4.8 \mathrm{~mm}$. respectively). Two days later still, when edema had quite disappeared, the cardiac output increased still further to 2550 cc. (173 per cent), cardiac size dimin-

2 "Relative blood flow" is a ratio between some state of flow and another, for example, between the arteriovenous oxygen difference per liter of blood in a normal cardiac mechanism and an abnormal one, the metabolism, that is to say, the oxygen consumption, remaining constant.

${ }^{3}$ This dog was given by stomach tube sodium chloride 15.0 grams (10 per cent solution) a day for 5 days. She was then given, in the same manner, sodium bromide 15.0 grams ( 10 per cent solution) a day for 5 days, when she became drowsy. Four days later (November 27, 1928) edema of the extremities was observed. Water was given in the morning with sodium chloride or sodium bromide, and milk and eggs in the evening to bring the total daily intake of fluid up to $1500 \mathrm{cc}$. The caloric value of the food intake was constant. 


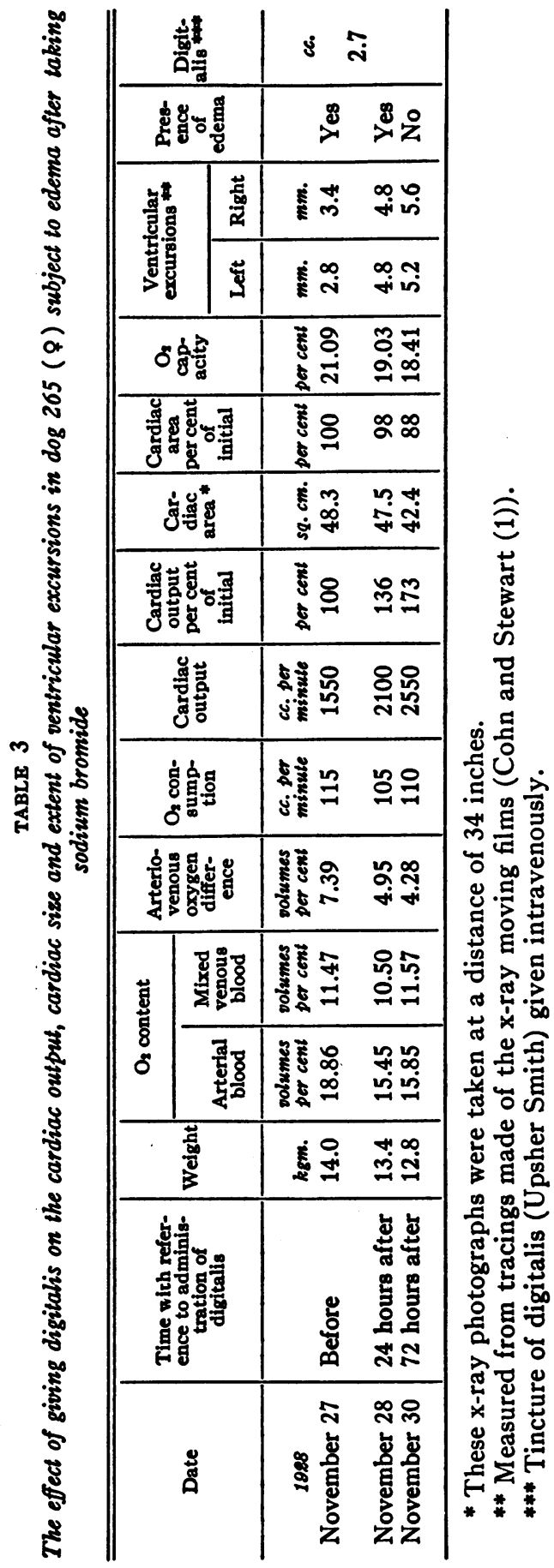




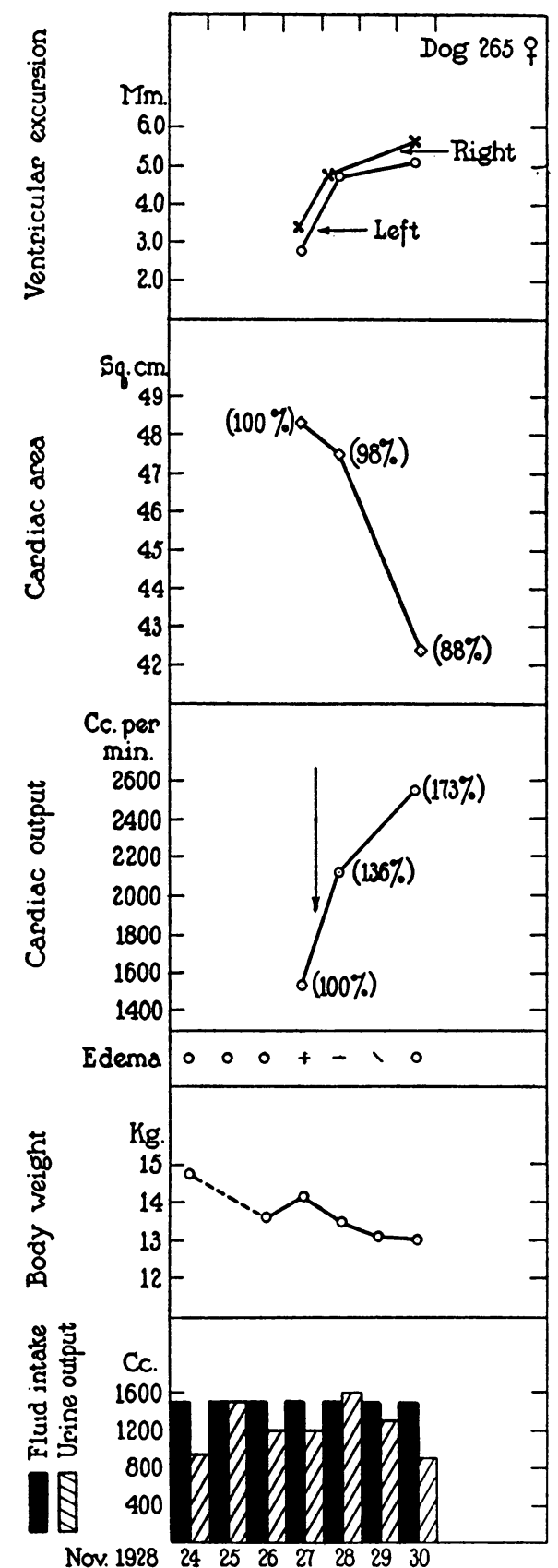

Fig. 5. In This Figure Is Shown the Effect of Giving Digitalis on Cardiac Output, Cardiac Size and Extent of Ventricular Excursions in Dog 265, Subject to Edema, the Result of Oral Ingestion of Sodium BROMIDE.

In interpreting the symbols relating to the presence of edema, $0=a b s e n t$, $+=$ present, $-=$ unchanged, and $\backslash=$ decreasing . 
ished further to 42.4 sq. $\mathrm{cm}$. (88.0 per cent), and the ventricular excursions increased to $5.2 \mathrm{~mm}$. (left) and $5.6 \mathrm{~mm}$. (right).

Summary: When digitalis was given to a dog, the subject of edema artificially induced, cardiac output increased, cardiac size diminished and the extent of ventricular excursions increased. The dog lost weight and became free of edema.

\section{DISCUSSION}

That the effect of giving digitalis to intact normal dogs is to decrease cardiac output and cardiac size and to increase ventricular excursions appears to be a fact $(1,17)$. Its effect in dogs in which the hearts were enlarged, but in which there was no evidence of heart failure has also been studied. In this situation, as in the normal one, the effect was to decrease cardiac output and cardiac size and to increase the extent of ventricular excursions (2). The effect of giving digitalis has been studied therefore under the following circumstances. First, in normal dogs the hearts of which were normal in size; second, in dogs the subject of muscular hypertrophy following the creation of artificial valvular lesions. In both these, the result is decrease in output. And now there is a case in which information was still lacking, namely, in intact, unanesthetized dogs in which the cardiac output is diminished and the heart dilated due to the action of auricular fibrillation artifically induced. The result is increase in cardiac output and decrease in cardiac size. Insufficient hearts become smaller, it seems, and, unlike normal hearts in which it decreases, increase their output as the result of a change dependent on the heart itself, and obviously independent of changes in a peripheral mechanism, such as that of the throttle action of the hepatic veins. The outstanding point is this, that at a time when the basic mechanism of the heart beat remained unchanged, the action of digitalis resulted in increase in output, though the rate decreased; occasionally it increased the output still more when the normal rhythm was restored, though the normal did not attain the fibrillatory rate.

In these observations and in the ones published in the third paper (22) parallel phenomena have been studied in dogs and in human beings, namely, the effect of giving digitalis to normal animals and to normal human beings on the one hand; on the other, the effect in dogs in which the cardiac output is diminished and dilatation is present, and in patients the subjects of heart failure, whose hearts are enlarged and their output diminished. The output, both in normal dogs and in normal men, as well as the size, decrease; in diseased human beings and in abnormal dogs during heart failure, increase in output and decrease in size take place. Discussion of these results will be found in a third report (22). It is sufficient to state now that digitalis seems to exert the same essential effects both 
in normal and diseased hearts; it decreases cardiac size, its effect on tone, and it increases the extent of ventricular contraction, its effect on contraction $(1,2)$.

Edema which results in dogs from the oral administration of large doses of sodium bromide is probably not analogous to edema occurring in heart failure. The mechanism of its occurrence is not clearly known. It is presumably the result of shifting of ions in the blood, so that bromide ions are substituted for chloride ions; in consequence of this process, water is retained in the tissues. The course of events following the administration of digitalis in this condition resembles that in heart failure in human beings, namely, the cardiac output increases, the cardiac size decreases and the extent of ventricular excursion increases.

\section{SUMMARY AND CONCLUSIONS}

1. During auricular fibrillation when the ventricular rate is rapid the cardiac output per minute is less than it is during the normal, slower sinus rhythm (3). In consequence of this abnormal rhythm in intact unanesthetized trained dogs the heart increases in size. This conclusion is based on a larger number of observations than was possible in an earlier paper (4).

2. When the cardiac output is diminished and the heart is dilated due to artificial auricular fibrillation, the administration of digitalis results in increase in cardiac output and decrease in cardiac size.

3. When the normal rhythm returns, the heart being, of course, still under the influence of digitalis, the output either increases, the size remaining unchanged (from that in the fibrillatory state), or both output and size decrease.

4. The observations show, as do the ones next to be reported, that digitalis has the same action in normal and in pathological hearts; it decreases cardiac size (an effect on tone). The amount of the cardiac output which results from this action depends upon the initial size of the heart; it decreases in normal hearts, and increases in dilated ones.

5. In a dog, the subject of edema due to taking sodium bromide, the administration of digitalis increased cardiac output, decreased cardiac size and increased the extent of ventricular excursions.

\section{BIBLIOGRAPHY}

1. Cohn, A. E., and Stewart, H. J., J. Clin. Invest., 1928, vi, 53. The Relation between Cardiac Size and Cardiac Output per Minute Following the Administration of Digitalis in Normal Dogs.

2. Cohn, A. E., and Stewart, H. J., J. Clin. Invest., 1928, vi, 79. The Relation between Cardiac Size and Cardiac Output per Minute Following the Administration of Digitalis in Dogs in Which the Heart is Enlarged. 
3. Stewart, H. J., and Gilchrist, A. R., J. Clin. Invest., 1928, v, 335. Studies of the Effect of Cardiac Irregularity on the Circulation. II. The Estimation of Cardiac Output in Dogs Subject to Artificial Auricular Fibrillation.

4. Stewart, H. J., and Crawford, J. H., J. Clin. Invest., 1927, iii, 483. The Effect of Regular and Irregular Tachycardias on the Size of the Heart.

5. Blalock, A., J. Lab. and Clin. Med., 1927, xii, 378. A Rubber Mask for Determination of Oxygen Consumption of the Dog.

6. Stewart, H. J., Crawford, J. H., and Hastings, A. B., J. Clin. Invest., 1926, iii, 435. The Effect of Tachycardia on the Blood Flow in Dogs. I. The Effect of Rapid Irregular Rhythms as Seen in Auricular Fibrillation.

7. Stewart, H. J., Crawford, J. H., and Gilchrist, A. R., J. Clin. Invest., $1928, v, 317$. Studies on the Effect of Cardiac Irregularity on the Circulation. I. The Relation of Pulse Deficit to Rate of Blood Flow in Dogs Subject to Artificial Auricular Fibrillation and to Regular Tachycardia.

8. Kolls, A. C., J. Pharm. and Exper. Therap., 1920, xv, 443. An Indirect Method for the Determination of Blood Pressure in the Unanesthetized Dog.

9. Kubie, L. S., J. Lab. and Clin. Med., 1925-26, xi, 186. A Substitute for the Rubber Bulb for Use in the Kolls and Erlanger Blood Pressure Instruments.

10. Stewart, H. J., J. Biol. Chem., 1925, lxii, 641. The Oxygen and Carbon Dioxide Contents of the Arterial and Mixed Venous Blood in Normal Intact Dogs.

11. Van Slyke, D. D., and Neill, J. M., J. Biol. Chem., 1924, 1xi, 523. The Determination of Gases in Blood and Other Solutions by Vacuum Extraction and Manometric Measurement. I.

12. Fick, A., Verhandl. d. Würzb. physikal.-med. Gesellsch., 1870, N. F. ii. S. xvi. der Sitzungsber. Ueber die Messung des Blutquantums in der Herzventrikeln.

13. Stewart, H. J., J. Clin. Invest., 1926, iii, 475. A Technique for Measuring $\mathrm{X}$-ray Photographs of the Cardiac Areas of Dogs.

14. Robinson, G. C., and Wilson, F. N., J. Pharm. and Exper. Therap., 1918, $\mathrm{x}, 491$. A Quantitative Study of the Effect of Digitalis on the Heart of the Cat.

15. Cohn, A. E. Unpublished experiments.

16. Pardee, H. E. B., J. Am. Med. Assoc., 1925, lxxxv, 1359. Hypodermic Digitalis Preparations.

17. Harrison, T. R., and Leonard, B. W., J. Clin. Invest., 1926, iii, 1. The Effect of Digitalis on the Cardiac Output of Dogs and Its Bearing on the Action of the Drug in Heart Disease.

18. Hastings, A. B., and van Dyke, H. B., J. Biol. Chem., 1928, lxxviii, p. xxxv. Studies of the Bromide and Chloride Distribution in the Blood of Dogs and the Production of Experimental Edema by Sodium Bromide Administration.

19. Hastings, A. B., and van Dyke, H. B., J. Biol. Chem., 1931, xcii, 13. Studies of Bromide Distribution in the Blood. I. In Vitro Experiments of Bromide and Chloride Distributions.

20. Hastings, A. B., and van Dyke, H. B., J. Biol. Chem., 1931, xcii, 27. Studies of Bromide Distribution in the Blood. II. The Distribution 
of Bromides and Chlorides in the Blood of Dogs Following the Oral Administration of Sodium Bromide.

21. Hastings, A. B., Harkins, H. N., and Liu, S. K., J. Biol. Chem., 1932, xciv, 681. Blood and Urine Studies Following Bromide Injection.

22. Stewart, H. J., and Cohn, A. E., J. Clin. Invest., 1932, xi, 917. Studies on the Effect of the Action of Digitalis on the Output of Blood from the Heart. III. Part 1. The Effect on the Output in Normal Human Hearts. Part 2. The Effect on the Output of Hearts in Heart Failure with Congestion, in Human Beings. 